\title{
Riqueza de fungos causadores de ferrugens em plantas hospedeiras da Região Metropolitana de Belém, PA, Brasil ${ }^{1}$
}

\author{
Luana Teixeira do Carmo ${ }^{2}$, Helen Maria Pontes Sotão ${ }^{2,3,7}$, Fabiano Melo de Brito ${ }^{4}$, Mônica Fecury Moura ${ }^{5}$ \\ Jamille Rabelo de Oliveira ${ }^{6}$
}

Recebido: 11.02.2016; aceito: 20.09.2016

\begin{abstract}
Richness of rust fungi on host plants in Belém Metropolitan Area, Pará State, Brazil). This study had as objectives: to survey the fungi that cause rust (Pucciniales) in RMB, to identify species of rust parasitizing plants of economic interest, and to present findings of new records to South America, Brazil, Amazon and Pará, thus broadening the knowledge of the richness of the group and the relationships with their host plants. Collections were made in RMB in 2011-2013 period, and the MG (MPEG) and IAN (EMBRAPA) herbaria were revised. The RMB presented 76 species and 20 genera of Pucciniales. Fourteen species are new records: South America (one), Brazil (one), Amazon (five), State of Pará (one), and RMB (six). Twenty species of rust parasitize plants of economic interest. The RMB has the highest Pucciniales richness in the Amazon.
\end{abstract}

Keywords: Amazon, phytopathogens, Pucciniales, survey

RESUMO - (Riqueza de fungos causadores de ferrugens em plantas hospedeiras da Região Metropolitana de Belém, PA, Brasil). Este estudo teve por objetivos inventariar os fungos causadores de ferrugens (Pucciniales) na RMB, identificar espécies de ferrugens que parasitam plantas de interesse econômico, apresentar novos registros para a América do Sul, Brasil, Amazônia e Estado do Pará, e assim ampliar o conhecimento sobre a riqueza do grupo e da relação com suas plantas hospedeiras. Foram realizadas coletas na RMB no período de 2011-2013, e revisados os herbários MG (MPEG) e IAN (EMBRAPA). A RMB apresentou 76 espécies e 20 gêneros de fungos Pucciniales. Quatorze espécies são novos registros: para a América do Sul (uma), Brasil (uma), Amazônia (cinco), Estado do Pará (uma) e RMB (seis). Vinte espécies de ferrugens parasitavam plantas de interesse econômico. A RMB apresenta a maior riqueza de espécies de Pucciniales estudada na Amazônia. Palavras-chave: Amazônia, fitopatógenos, inventário, Pucciniales

\section{Introdução}

Os fungos da ordem Pucciniales formam um grupo numeroso de organismos fitopatogênicos com ampla diversidade e distribuição mundial (Buriticá 2003). O mesmo autor estima existir cerca de 20.000 a 24.000 espécies, porém apenas cerca de 8000 espécies estão descritas e classificadas em 120 gêneros e 13 famílias do filo Basidiomycota, subfilo Pucciniomycotina, classe Pucciniomycetes (Aime et al. 2006, Hibbett et al. 2007, Kirk 2008).
No Neotrópico, o Brasil é considerado o país mais diverso e melhor estudado quanto aos fungos Pucciniales (Salazar-Yepes \& Carvalho Jr. 2010, Berndt 2012). Dados copilados por Hennen et al. (2005) e Carvalho Jr. \& Sotão (2010, 2016), com base em material depositado em herbários ou citados em literatura, registram cerca de 750 espécies e 66 gêneros desta Ordem para o país, das quais 184 são conhecidas para a região Norte e entre estas, 66 espécies e 3 gêneros tem distribuição exclusiva para esta região.

1. Parte da Dissertação de Mestrado da primeira Autora

2. Universidade Federal Rural da Amazônia, programa de Pós-graduação em Ciências Biológicas - Botânica Tropical, Av. Tancredo Neves, 2.501, Terra Firme, 66077-830 Belém, Pará, Brasil

3. Museu Paraense Emílio Goeldi, Coordenação de Botânica, Avenida Perimetral, 1.901, Terra Firme, Caixa postal 399, 66.040-170 Belém, Pará, Brasil

4. Universidade Federal Rural da Amazônia, programa de Pós-graduação em Agronomia, Av. Tancredo Neves, 2.501, Terra Firme, 66.077-830 Belém, Pará, Brasil

5. Universidade Estadual Paulista Júlio de Mesquita Filho, Faculdade de Ciências Agronômicas de Botucatu, Rua João Montes Filho Parque Residencial Primavera, Caixa postal 48, 18.610-370 Botucatu, SP, Brasil

6. Universidade Federal do Ceará, Programa de Pós-graduação em Agronomia/Fitotecnia, Av. Mister Hull Campus Pici, 60.455-760 Fortaleza, Ceará, Brasil

7. Autor para contato: helen@museu-goeldi.br 
No Bioma Amazônia, o Estado do Pará tem a maior riqueza conhecida, com 115 espécies (Carvalho Jr. \& Sotão 2016).

A Região Metropolitana de Belém (RMB) abrange os municípios de Ananindeua, Marituba, Santa Bárbara, Benevides e Belém, no Estado do Pará (Ferreira et al. 2012). A cobertura vegetal é formada principalmente por florestas secundárias de terra firme, florestas de várzea nas áreas mais baixas, florestas de igapó e manguezais, e na área urbana encontram-se pomares, hortas, quintais, vegetação ruderal, regiões arborizadas nas ruas e praças, e no passado, a vegetação primária desta região tinha o domínio de extensas áreas de florestas de terra firme, mas com as alterações que sofreram ao longo do tempo foram substituídas por vegetações secundárias (Silva 2011, Ferreira et al. 2012). Nesta região ainda existem vários fragmentos florestais resguardados em unidades de conservação, tanto públicas quanto particulares (Amaral et al. 2009, Ananindeua 2011, Ferreira et al. 2012).

A RMB está inserida no Centro de Endemismo Belém, uma região conhecida como "arco do desmatamento", considerado um dos mais ameaçados centros de endemismo da Amazônia. Tem sido alvo do desmatamento e extração seletiva de madeira que, por sua vez, causa a perda de habitat e a degradação e fragmentação florestal (Almeida \& Vieira 2010). Várias partes deste centro de endemismo, incluindo a RMB, estão classificadas pelo Ministério do Meio Ambiente como áreas de extremamente alta e muito alta importância biológica e de extremamente alta prioridade para a conservação (MMA, 2007).

Amaral et al. (2009), relatam em um levantamento botânico realizado em fragmentos florestais da RMB, a existência de mais de 759 espécies de plantas. Tal riqueza de espécies despertou o interesse em conhecer os fungos da ordem Pucciniales que podem estar parasitando hospedeiros nos tipos florestais da área.

Trabalhos que relacionam ferrugens coletadas na RMB desde o início do século XIX são os de Hennings (1900, 1902, 1908), Dietel (1909), Sydow \& Sydow (1916), Batista et al. (1966), Albuquerque (1971a, 1971b), Albuquerque \& Figueiredo (1971), Hennen \& Freire (1979), Hennen \& Sotão (1996), estando a maioria dos espécimes identificados depositados nos herbário João Murça Pires (MG), do Museu Paraense Emílio Goeldi (MPEG) e da Embrapa Amazônia Oriental (IAN), coleções de referência para os fungos da Amazônia.
Este estudo teve por objetivos inventariar os fungos causadores de ferrugens (Pucciniales) na RMB, identificar espécies de ferrugens que parasitam plantas de interesse econômico, apresentar novos registros para a América do Sul, Brasil, Amazônia e Estado do Pará e, assim ampliar o conhecimento sobre a riqueza do grupo e da relação com suas plantas hospedeiras.

\section{Material e métodos}

Este estudo foi realizado com novos espécimes coletados pelos autores em áreas da RMB e com espécimes de Pucciniales depositados nos herbários MG, do Museu Paraense Emílio Goeldi e IAN, da Embrapa Amazônia Oriental, procedentes de coletas anteriores na RMB.

As coletas de amostras de plantas parasitadas por ferrugens foram realizadas em áreas de unidades de conservação (UC's), ilhas, áreas urbanizadas, jardins e praças da RMB (tabela 1), entre os anos de 2011 a 2013, totalizando 40 dias de coleta. Para a etapa de coleta foi adotada a metodologia empregada para este grupo de fungos (Cummins \& Hiratsuka 2003, Fidalgo \& Bononi 1989, França et al. 2009).

A identificação e/ou confirmação de todos os espécimes analisados, foi realizada a partir do estudo de caracteres morfológicos, em lâminas montadas em lactoglicerol para observação das microestruturas dos fungos (Cummins \& Hiratsuka 2003) e apoiado em literatura especializada, contendo a descrição dos táxons, tais como os trabalhos de Hennen et al. (2005), Salazar-Yepes \& CarvalhoJr.(2010), França \& Sotão (2009), Sotão et al. (2009, 2013), além de comparação com os espécimes depositados nos herbários acima citados.

O sistema de classificação adotado para os gêneros e para as famílias de Pucciniales foi de Cummins \& Hiratsuka (2003). Os táxons dos espécimes estudados foram atualizados de acordo com nomenclatura aceita nos sites Index fungorum (2015) e Mycobank (2015).

A identificação das plantas hospedeiras foi feita por botânicos e técnicos em botânica do MPEG. O material testemunho foi depositado no herbário João Murça Pires (MG) do Museu Paraense Emílio Goeldi.

São apresentadas discussão, ilustrações e comentários taxonômicos para os novos registros para a América do Sul e Brasil. Dois novos registros para a Amazônia que não havia ilustrações em literatura, também foram ilustrados. Para todas as espécies são apresentadas indicações para ilustrações e/ou descrições, exceto para as espécies que estão determinadas até o nível de gênero. 
A riqueza de espécies foi estimada através dos estimadores Chao 1, Chao 2, Jacknife 1 e Jacknife 2 com auxílio do programa EstimateS 8.0 (Colwell 2006), considerando somente os espécimes e espécies coletados neste estudo.

\section{Resultados e Discussão}

As espécies encontradas foram classificadas nas famílias Chaconiaceae (Achrotelium, Chaconia, Maravalia, Olivea), Coleosporiaceae (Coleosporium), Phakopsoraceae (Cerotelium, Crossopsora, Kweilingia, Phakopsora, Phragmidiella), Pucciniaceae (Puccinia, Uromyces), Pucciniosiraceae (Pucciniosira), Raveneliaceae (Ravenelia, Sphenospora), Uropyxidaceae (Porotenus, Prospodium, Sorataea). Aecidium e Uredo não são classificados em famílias por se tratarem de gêneros de fases anamórficas.

Foram analisados 374 espécimes de fungos causadores de ferrugens, sendo 260 espécimes coletados neste estudo e 114 procedentes do levantamento nos herbários MG (64) e IAN (50), de períodos entre 1899 a 2006, procedentes principalmente do Jardim Botânico Bosque Rodrigues Alves, da Embrapa e do Parque do GUNMA. Como resultado foram registradas 76 espécies, uma variedade e 20 gêneros da ordem Pucciniales para a RMB (figura 1, tabela 2)

Quando consideradas apenas as coletas recentes realizadas, foram identificados 14 gêneros e 44 espécies, das quais 14 representam um acréscimo à lista de ferrugens conhecidas anteriormente e 24 espécies foram recoletadas, e seis espécimes foram identificados apenas até gênero, pois os espécimes apresentavam somente a fase uredinial, o que não foi suficiente para determinação do epíteto especifico.
Quando considerados apenas o reestudo dos espécimes já depositados nos herbários, foram identificados 19 gêneros e 56 espécies de ferrugens (figura 1).

Foram encontrados oito novos registros: para a América do Sul, Aecidium alibertiae Arthur sobre Alibertia spp. (Rubiaceae); para o Brasil, Uredo philodendri Pardo-Card. sobre Philodendron sp. (Araceae); para a Amazônia, Sphenospora kevorkianii Linder sobre Polystachya estrellensis (Orchidaceae), Aecidium cordiae Henn. sobre Cordia sp. (Boraginaceae), Puccinia commelinae Holw. sobre Commelina sp. (Commelinaceae), Phakopsora tecta H.S. Jacks. \& Holw. sobre Commelina virginica L. (Commelinaceae-IAN) e Puccinia hyptidis-mutabilis Mayor sobre Hyptis sp. (Lamiaceae); e para o Pará: Coleosporium plumeriae Pat., sobre Plumeria sp. (Apocynaceae). Apesar de o gênero Achrotelium ter sido encontrado anteriormente na Amazônia, nos Estados do Pará e Amapá (Carvalho Jr. \& Sotão 2010), ele é registrado pela primeira vez na RMB através da identificação da espécie Achrotelium lucumae (Arthur \& J.R. Johnst.) Cummins. Além desses, são novos registros para a RMB Aecidium amazonense Henn., Phragmidiella bignoniacearum (W.T. Dale) Buriticá \& J.F. Hennen, Puccinia flavovirens H.S. Jacks. \& Holw., Puccinia palicoureae Mains. e Uredo anthurii Har.

A família mais representativa observada foi Pucciniaceae com 30 táxons e o gênero com maior riqueza foi Puccinia, com 24 táxons, seguido de Uredo e Aecidium com onze e sete espécies respectivamente. Puccinia é o gênero mais rico em espécies na ordem Pucciniales, apresentando cerca de 3.000 a 4.000 espécies segundo Cummins \& Hiratsuka (2003), e de maior riqueza entre os fungos conhecidos para o

Tabela 1. Tabela 1. Locais de coleta de espécimes na Região Metropolitana de Belém, PA, Brasil. Unidades de conservação, com as cidades na qual estão localizadas e coordenadas geográficas.

Table 1. Collection sites of specimens in the Belém metropolitan area, Pará State, Brazil. Protected areas, cities where they are located, and geographic coordinates.

\begin{tabular}{lcc}
\hline Cidade da RMB & Unidade de Conservação/ ilhas & Coordenada Geográfica \\
\hline Ananindeua e Belém & Parque Estadual do Utinga-PEUTi & $1^{\circ} 25^{\prime} 22,3 \mathrm{~S} / 48^{\circ} 26^{\prime} 19,1^{\prime \prime} \mathrm{W}$ \\
Belém & Parque Ecológico do Município de Belém “Gunnar Vingren" & $1^{\circ} 23^{\prime} 54,4^{\prime \prime} \mathrm{S} / 048^{\circ} 27^{\prime} 48,4^{\prime \prime} \mathrm{W}$ \\
Belém & Bosque Rodrigues Alves/ Jardim Botânico da Amazônia & $1^{\circ} 25^{\prime} 50^{\prime \prime} \mathrm{S} / 48^{\circ} 27^{\prime} 23^{\prime \prime} \mathrm{W}$ \\
Belém & Área de Pesquisas ecológicas do Guamá (Embrapa)-APEG & $1^{\circ} 26^{\prime} 20^{\prime \prime} \mathrm{S} / 48^{\circ} 25^{\prime} 18^{\prime \prime} \mathrm{W}$ \\
Belém & Área de Proteção ambiental da ilha do Combu & $1^{\circ} 29^{\prime} 46,85^{\prime \prime} \mathrm{S} / 48^{\circ} 27^{\prime} 36,53^{\prime \prime} \mathrm{W}$ \\
Belém & Ilha de Cotijuba & $1^{\circ} 13^{\prime} 27,3^{\prime \prime} \mathrm{S} / 48^{\circ} 32^{\prime} 03,2^{\prime \prime} \mathrm{W}$ \\
Marituba & Reserva Ambiental da Pirelli & $1^{\circ} 27^{\prime} 45,28^{\prime \prime} \mathrm{S} / 48^{\circ} 18^{\prime} 4,57^{\prime \prime} \mathrm{W}$ \\
Santa Bárbara & Parque Ecológico de GUNMA & $1^{\circ} 12^{\prime} 14^{\prime \prime} \mathrm{S} / 48^{\circ} 17^{\prime} 39^{\prime \prime} \mathrm{W}$ \\
\hline
\end{tabular}




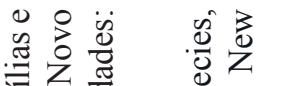

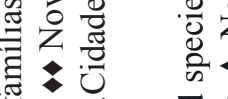

के

范实

ชั

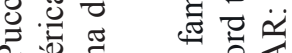

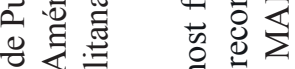

व

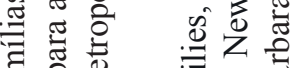

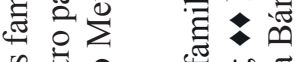

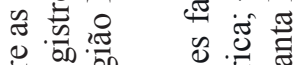

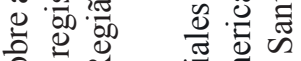

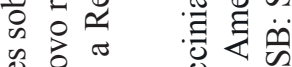

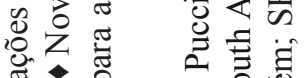

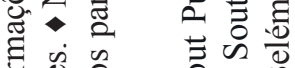

है

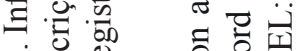

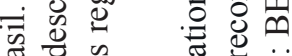

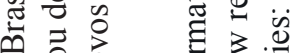

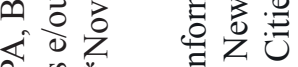

ป * ज

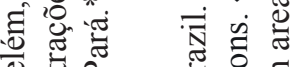

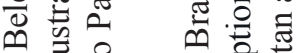

응용

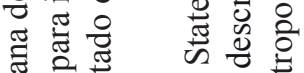

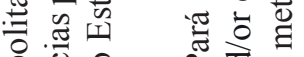

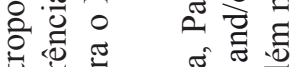

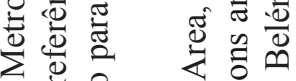

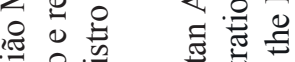

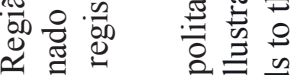

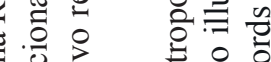

응

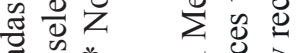

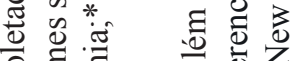

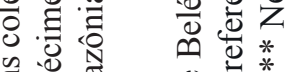

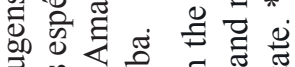

है

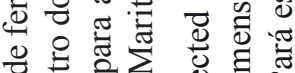

娄

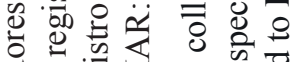

क्ष

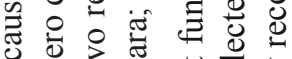

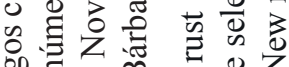

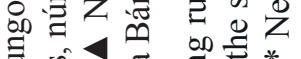

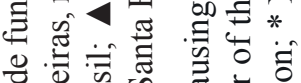

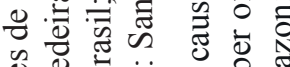

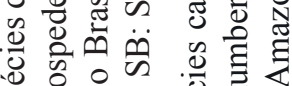

岂。

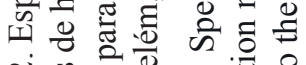

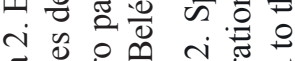

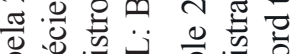

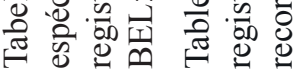

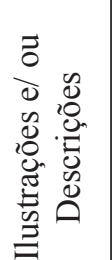

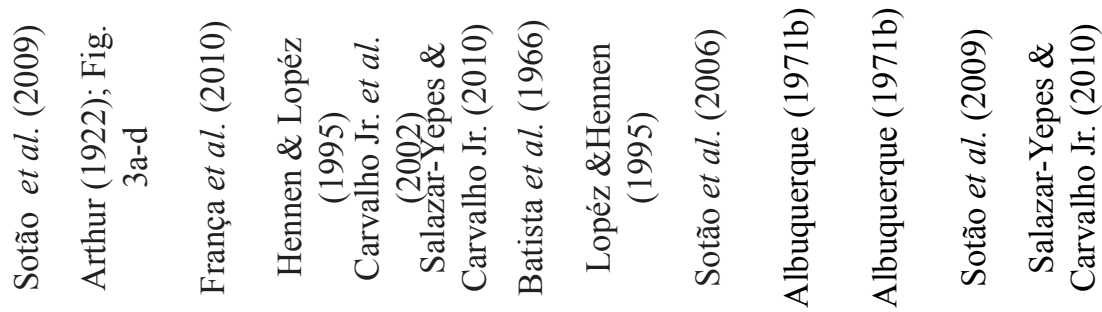

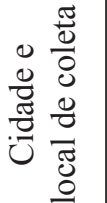

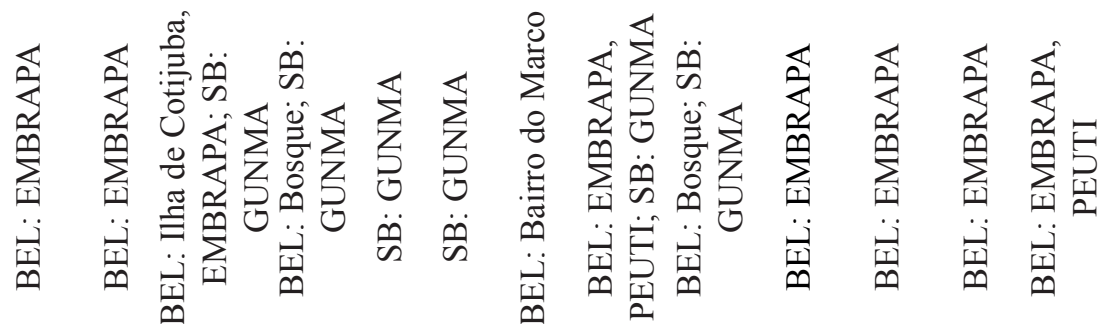

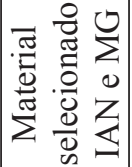

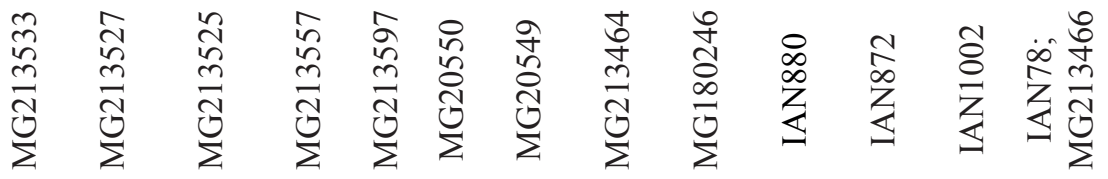

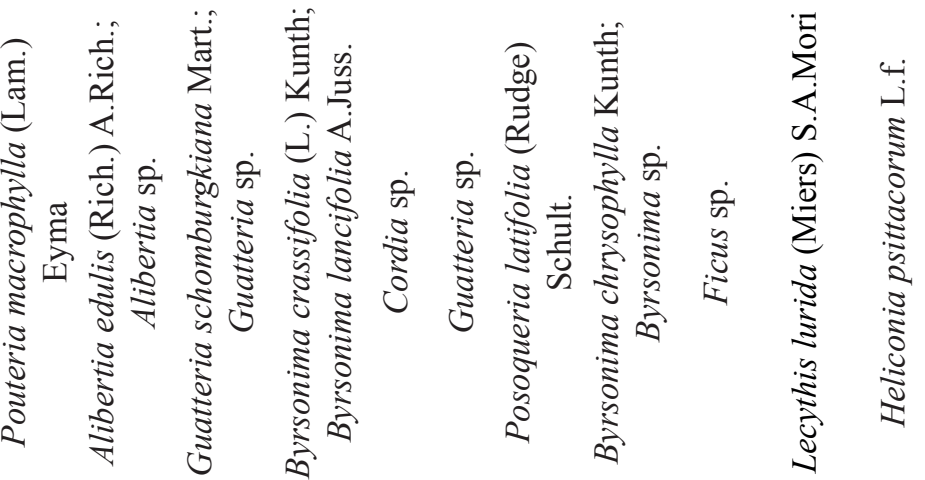

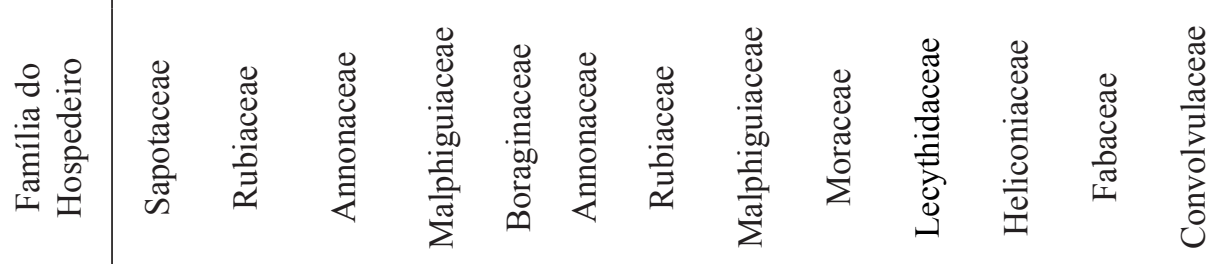

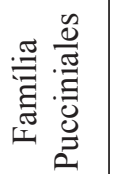

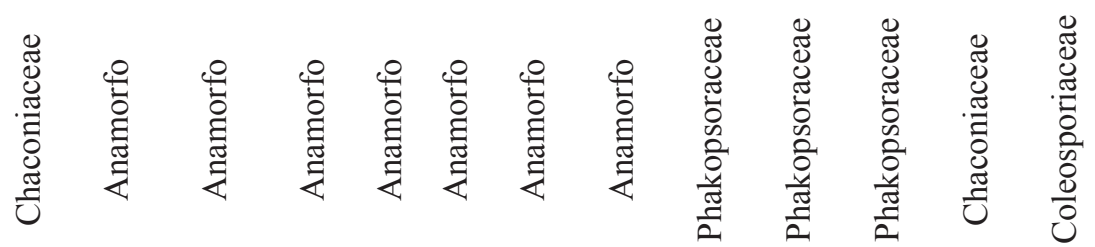

o

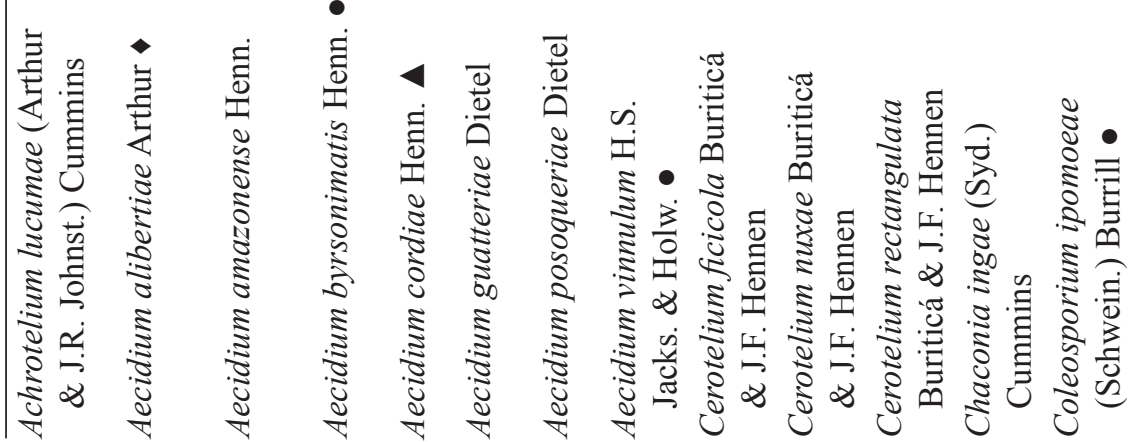




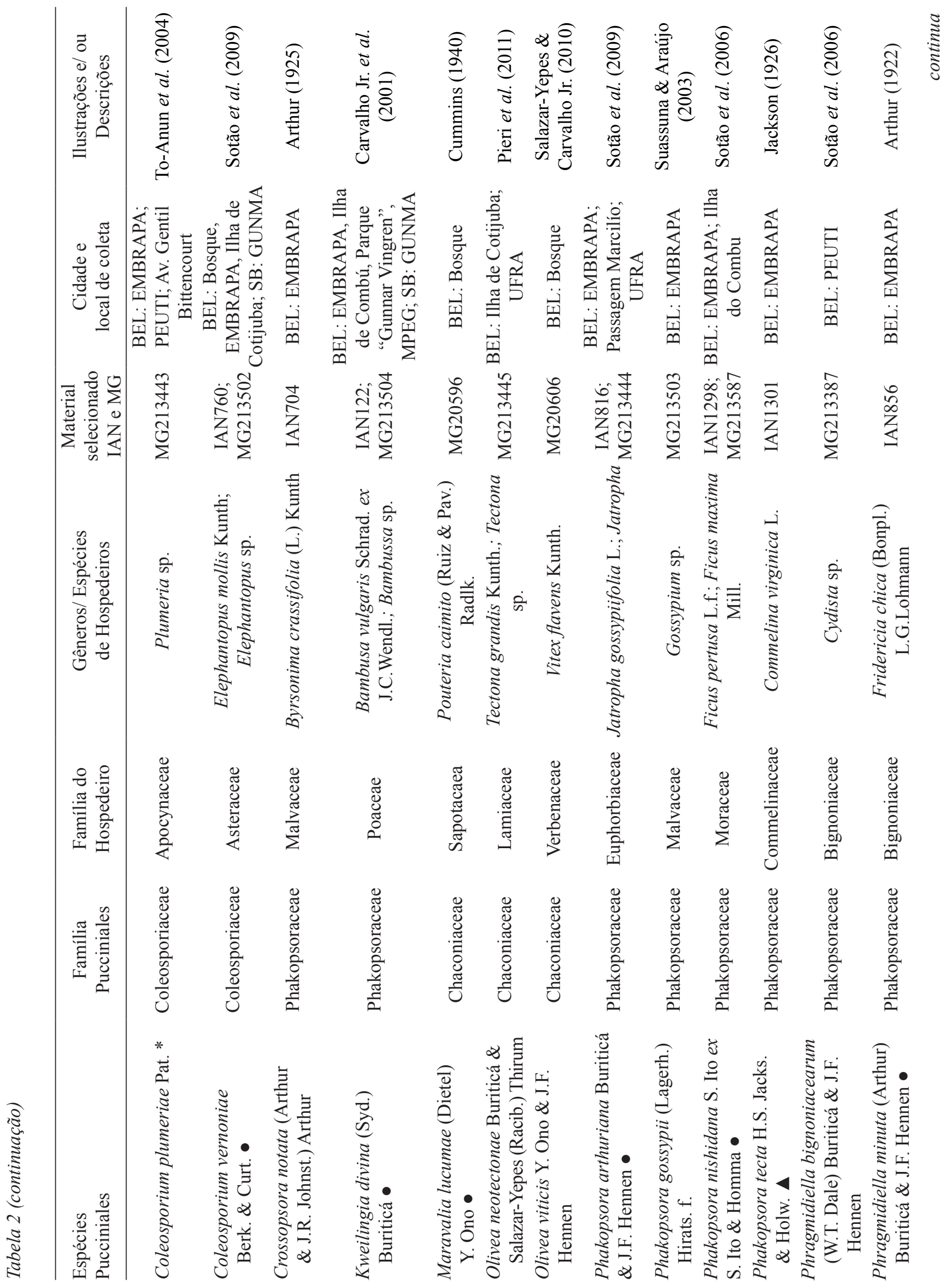




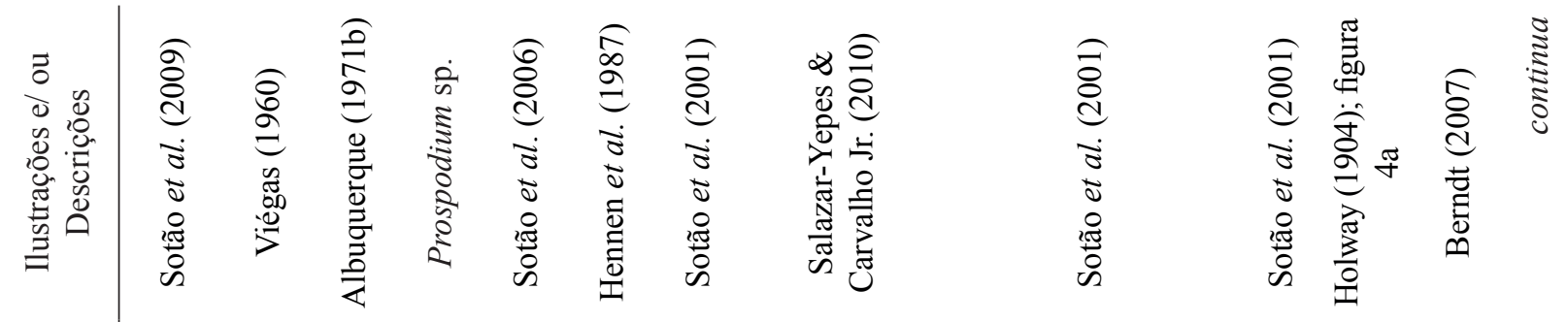

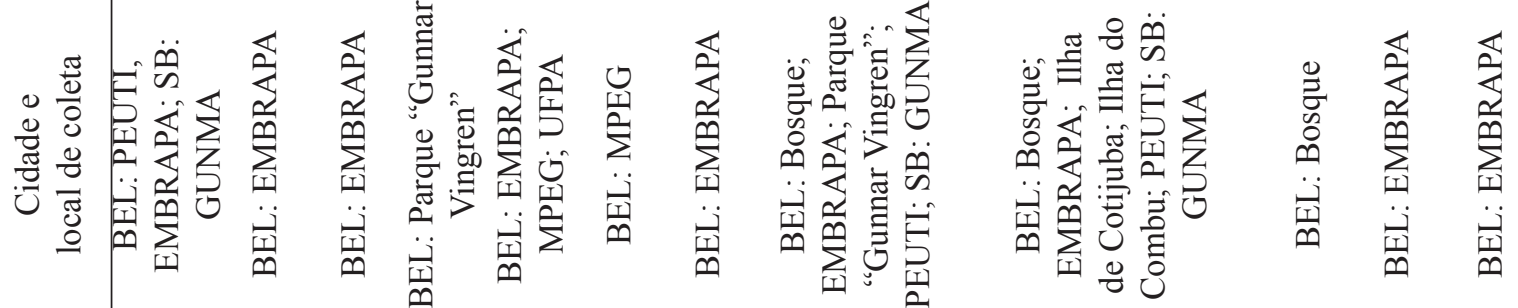

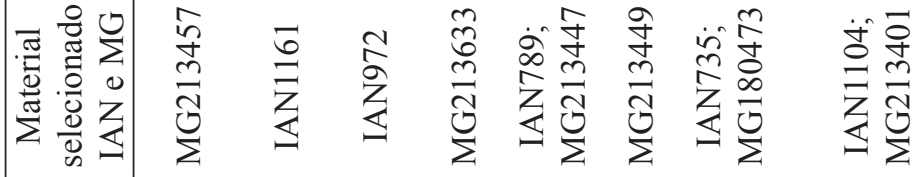

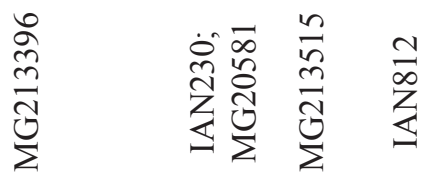

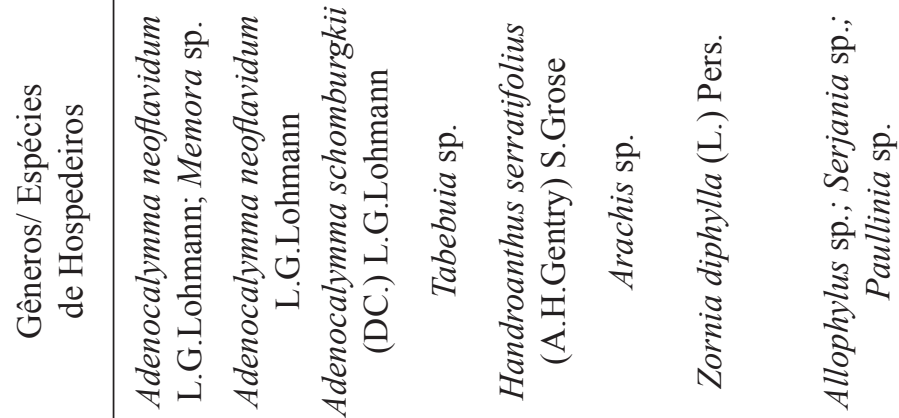

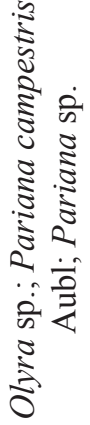

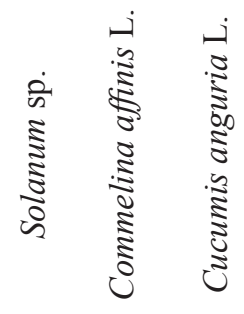

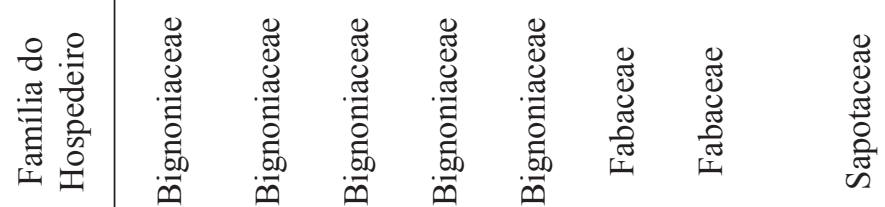

芯

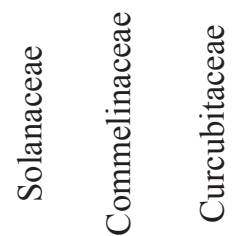

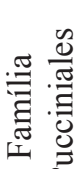
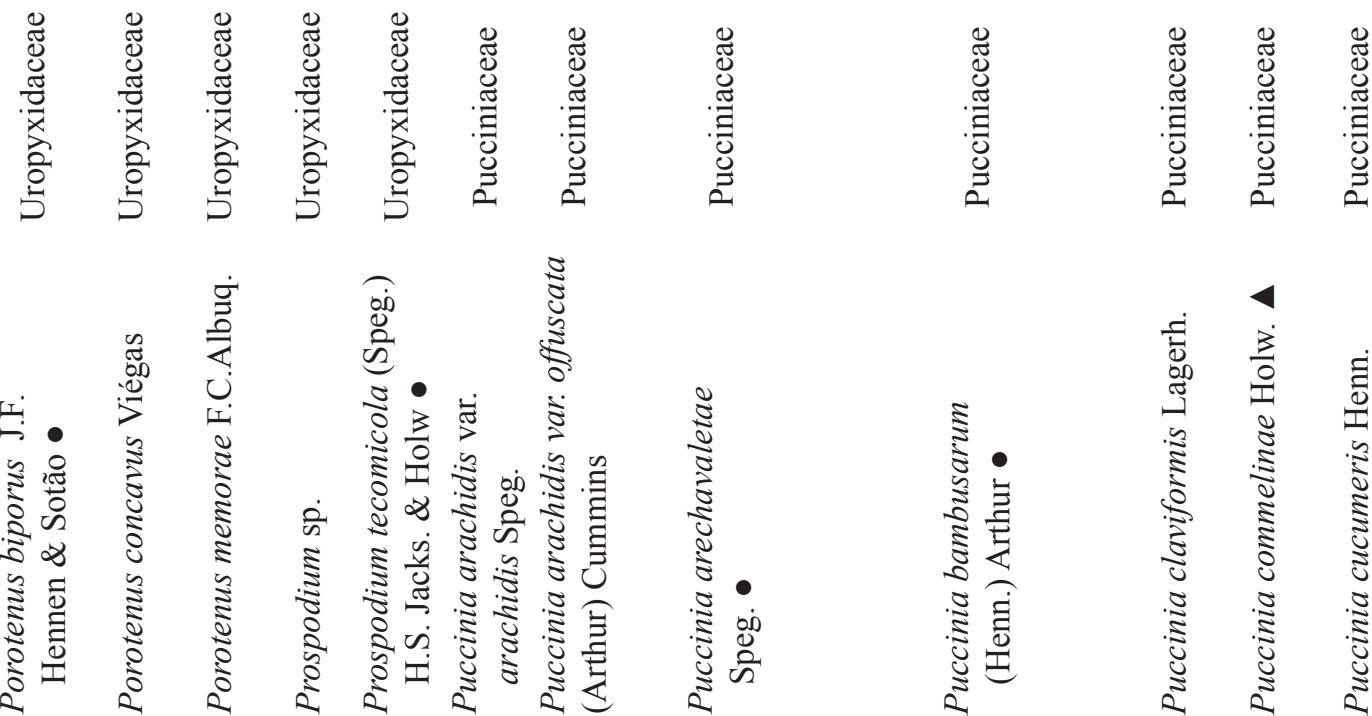

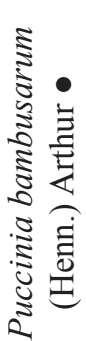

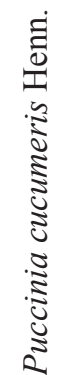




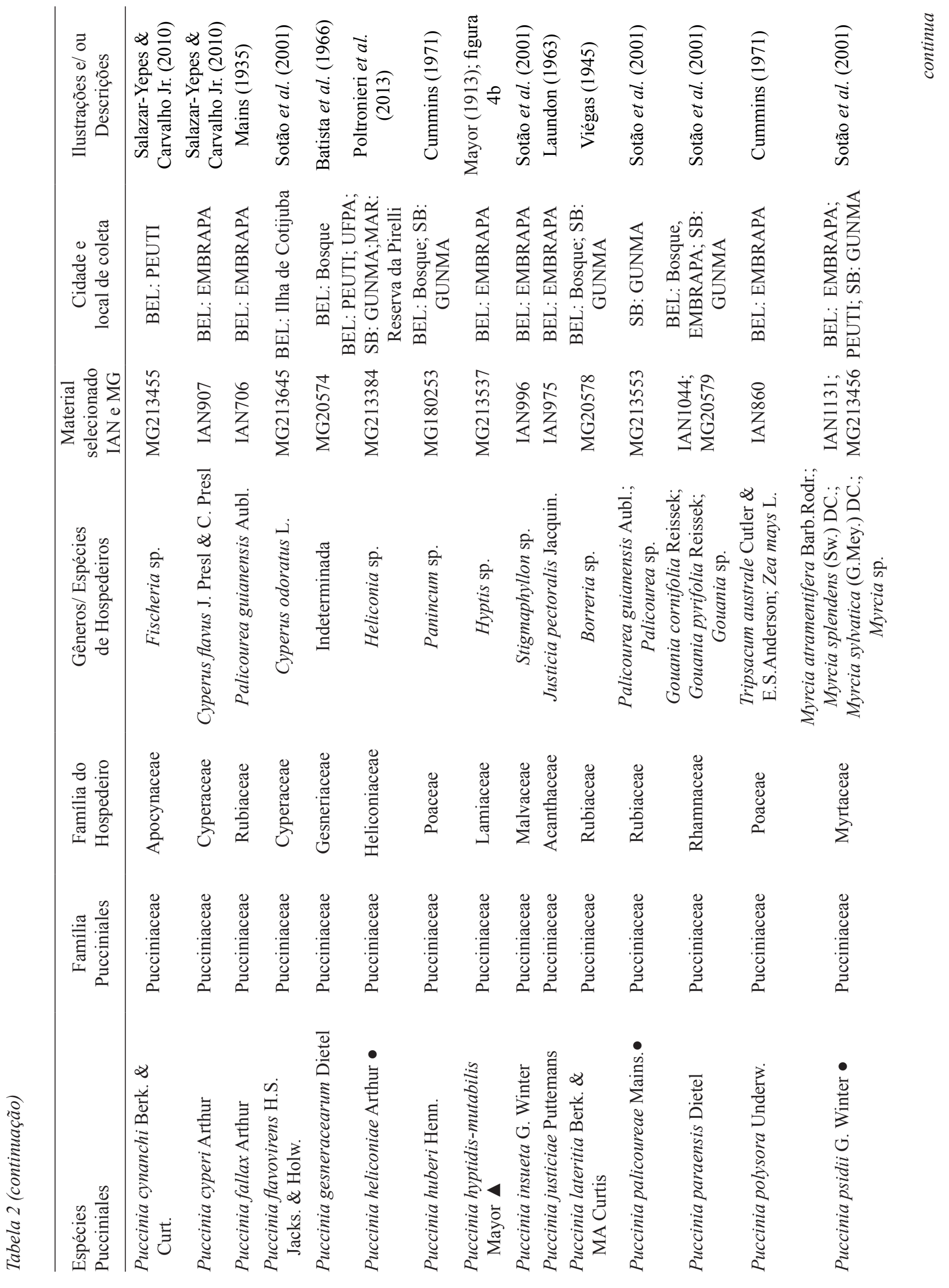




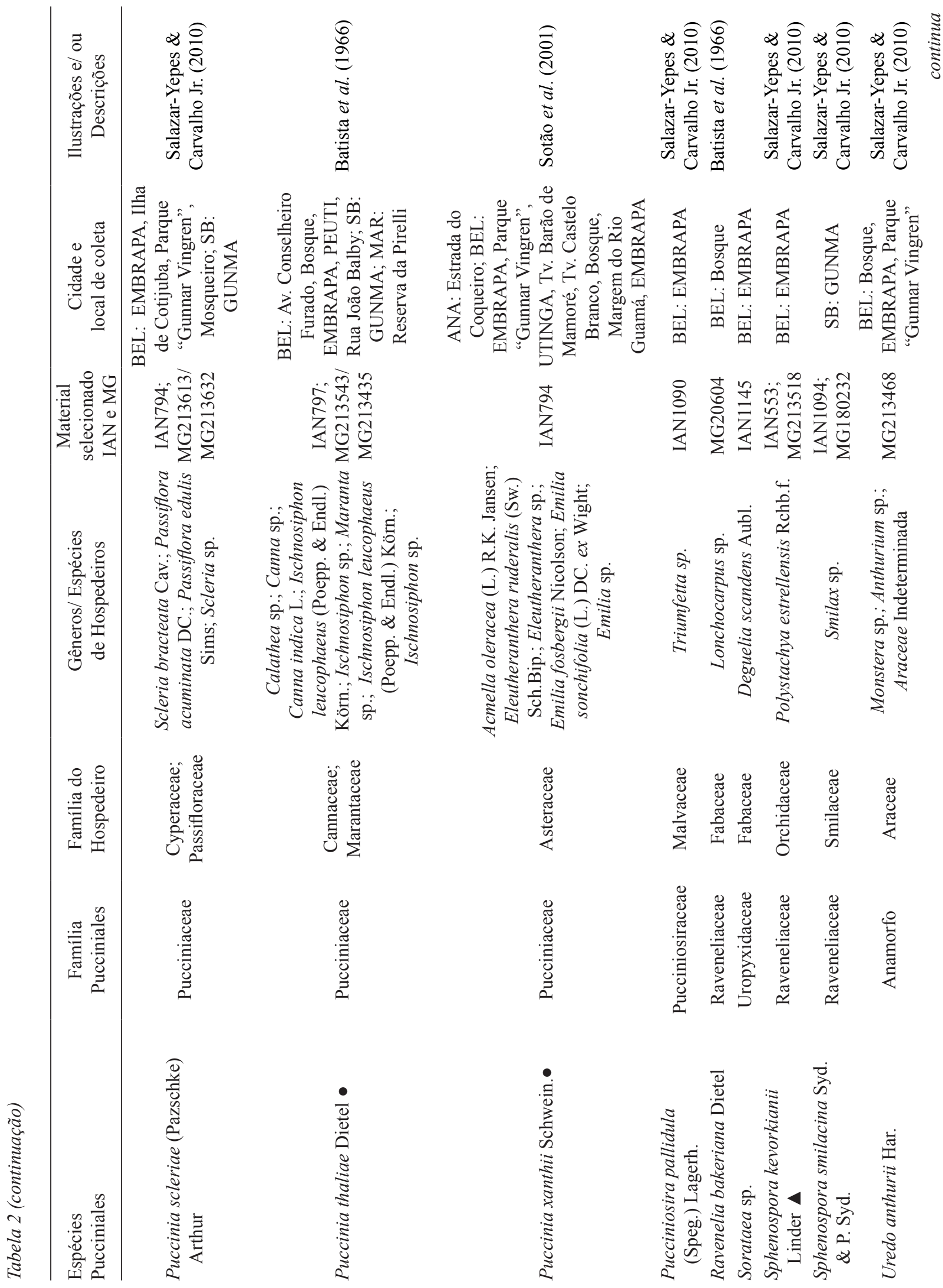




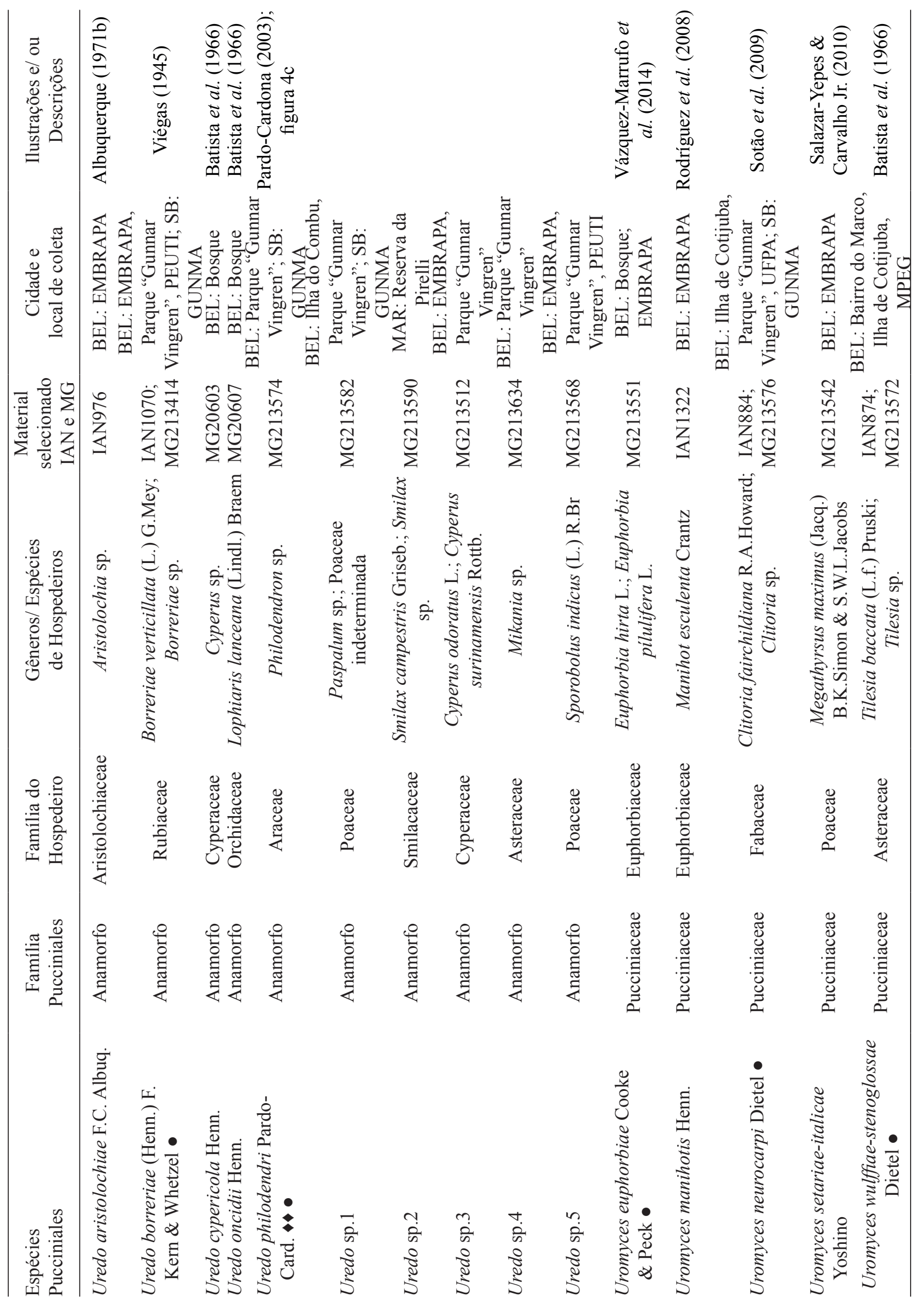


Brasil (Maia et al. 2015). Em outros levantamentos na Amazônia, realizados nos Estados do Amapá e Pará, o gênero Puccinia tem sido o mais rico em espécies (França et al. 2010, Sotão et al. 2001, 2009).

O PEUti foi a UC melhor amostrada em dias de campo (20 dias), entretanto, não foi a mais rica em espécies. Entre as UC's inventariadas, a área da EMBRAPA, com 18 espécies foi a de maior riqueza, seguida do PEUTi, GUNMA e do parque "Gunnar Vingren" com 14, 10 e 9 espécies respectivamente (tabela 2). As demais áreas de proteção amostradas apresentaram até cinco espécies. O esforço amostral foi diferenciado entre as UC's, o que dificulta uma possível análise comparativa entre as mesmas.

Para as áreas de coleta fora de UC's, na ilha de Cotijuba foram registradas 10 espécies, e outras 12 foram coletadas em áreas urbanizadas, como ruas, praças e jardins, e no entorno das unidades de conservação estudadas.

A flora dos remanescentes florestais da RMB foi considerada por Amaral et al. (2009) de alta riqueza de espécies endêmicas, mas Berndt (2012) argumenta que a riqueza de espécies de ferrugem não é impulsionada unicamente pela riqueza de espécies de plantas, mas sim pela composição da flora, em relação à porcentagem de famílias e gêneros de plantas hospedeiras de diferentes espécies de ferrugens. Isso pode explicar a menor riqueza de fungos no PEUTi, onde a riqueza de hospedeiras foi menor também em relação à EMBRAPA.

Os estimadores de riqueza utilizados neste estudo apresentaram os valores de 55 (Chao 1), 63 (Chao 2,

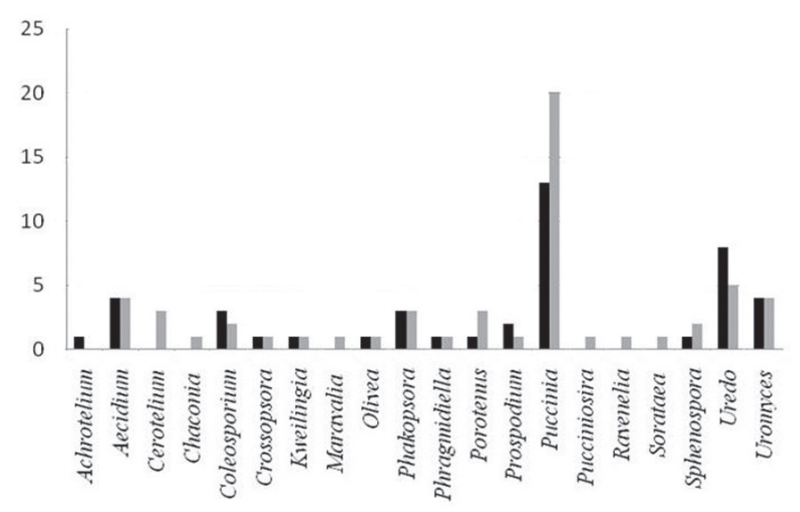

Figura 1. Número de espécies de Pucciniales por gênero, apresentados para a Região Metropolitana de Belém, PA, Brasil. Material coletado (barra preta) e presente nos herbários (MG e IAN) (barra cinza).

Figure1.Number of Pucciniales species per genus in presented for Belém metropolitan area, Pará State, Brazil. Collected material (black bar) and material present in the herbaria (gray bar) (MG and IAN).
Jacknife 1) e 73 (Jacknife 2), superiores a riqueza observada (44). Sugerindo que há necessidade de ampliar o esforço amostral. Porém, incluindo as espécies já registradas e as depositadas nos herbários, a riqueza da área da RMB (76), é superior às estimadas neste estudo. Sendo superior aos dados registrados em outros estudos do bioma Amazônia, como os de Sotão et al. (2013), para a Floresta Nacional de Caxiuanã, no Estado do Pará (72) e Berndt (2013), para a Guiana Francesa (68).

A limitação do método de coleta utilizado relacionada às coletas em árvores altas, das quais não foi possível observar a copa, e, por isso, não foram examinadas as folhas que poderiam estar parasitadas por ferrugens. Isto pode ser exemplificado pela hospedeira Lecythis lurida (Miers) S.A.Mori (Lecythidaceae) descrita como uma árvore de até $35 \mathrm{~m}$ de altura (Mori et al. 2014), coletada na EMBRAPA em 1965 (IAN 880) e descrita como tipo do anamorfo de Cerotelium nuxae Buriticá \& J.F. Hennen, que não foi recoletada. É de se supor que a planta ainda fosse jovem e mais baixa na época da coleta.

As espécies listadas para a RMB estão parasitando um total de 72 gêneros de plantas, classificados em 34 famílias botânicas (tabela 2). As plantas hospedeiras coletadas neste estudo foram classificadas em 24 famílias e 50 gêneros. As famílias Apocynaceae, Boraginaceae e Lamiaceae, representam seu primeiro registro como plantas hospedeiras de ferrugens na RMB, assim como os gêneros Alibertia (Rubiaceae), Anthurium e Monstera (Araceae), Arachis (Fabaceae), Calathea e Maranta, (Marantaceae), Cordia (Boraginaceae), Cydista (Bignoniaceae), Gossypium (Malvaceae), Hyptis (Lamiaceae), Mikania (Asteraceae), Paspalum e Sporobolus (Poaceae), Plumeria (Apocynaceae), Scleria (Cyperaceae). O gênero Allophylus (Sapindaceae) é registrado pela primeira vez no Brasil como hospedeiro de Puccinia arechavaletae Speg.

As famílias de hospedeiros com maior número de ferrugens foram Bignoniaceae e Poaceae com sete espécies cada, seguidas por Rubiaceae (seis), Fabaceae (seis), Cyperaceae (cinco) e Asteraceae (quatro) (figura 2).

Salazar-Yepes \& Carvalho Jr. (2013) em estudos no bioma Mata Atlântica, reconhecem Asteraceae, Leguminosae (Fabaceae) e Poaceae entre as que apresentam maiores riquezas de ferrugens no Brasil. Essas Famílias também constam como as mais ricas em hospedeiros em vários estudos nos diferentes continentes (Berndt 2012). Para o Bioma Amazônia, 
Sotão et al. (2009) e França et al. (2010) em estudos realizados no Pará e no Amapá, respectivamente, registraram estas famílias entre as mais representadas em número de ferrugens,e a família Bignoniaceae entre as de maior riqueza de ferrugem para a região Norte.

As famílias que apresentaram o maior número de indivíduos coletados foram Poaceae (43), seguida por Sapindaceae (38), Heliconiaceae (30) e Asteraceae (28). Os gêneros com o maior número de indivíduos coletados foram Serjania (Sapindaceae) e Heliconia (Heliconiaceae) com 30 espécimes, seguido por Pariana (Poaceae) com 22 espécimes. Consequentemente, os fungos que as parasitam também foram os mais registrados: Puccinia arechavaletae, $P$. heliconiae e P. bambusarum, respectivamente.

No levantamento dos herbários IAN e MG foram registrados 29 famílias e 51 gêneros de plantas hospedeiras de fungos Pucciniales. As famílias Acanthaceae, Cucurbitaceae, Gesneriaceae, Lecythidaceae, Rhamnaceae, Solanaceae e Verbenaceae foram registradas somente no material dos herbários, assim como as ferrugens que parasitam essas famílias (tabela 2).

Uma das características deste grupo de fungos é sua alta especificidade em relação aos seus hospedeiros (Cummins \& Hiratsuka 2003). Neste estudo, porém, observamos que a espécie Puccinia thaliae foi registrada ocorrendo em duas famílias: Cannaceae e Marantaceae. Estas duas famílias são incluídas

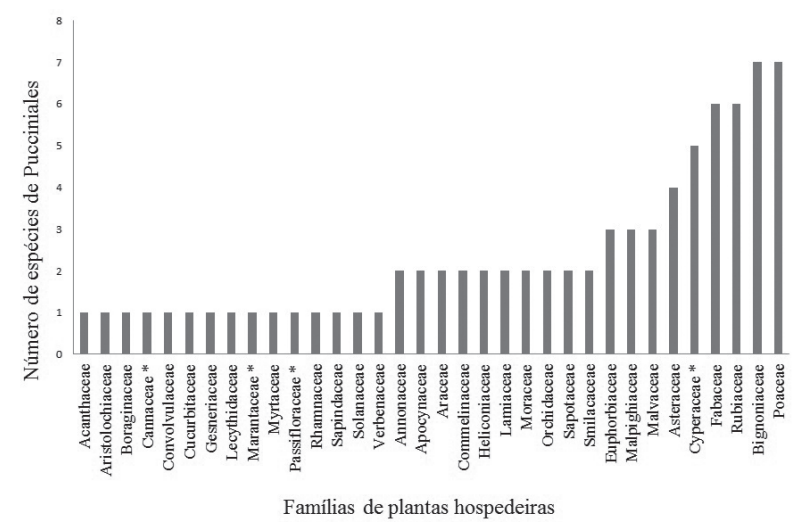

Figura 2. Número de espécies de fungos causadores de ferrugens por família de plantas hospedeiras coletadas na Região Metropolitana de Belém, PA, Brasil. *Famílias que apresentam alguma espécie de ferrugens em comum.

Figure 2. Number of rust fungi species per family of host plants collected in Belém metropolitan area, Pará State, Brazil. * Families that present rust species in common. na ordem Zingiberales, aceita como monofilética e formam o clado Cannaceae + Marantaceae, ou seja, apresentam afinidades filogenéticas (Kress \& Spech 2005). Esta afinidade filogenética entre as famílias pode explicar a capacidade de $P$. thaliae de parasitar famílias distintas, com os mesmos estágios esporíferos em ambas.

Vinte espécies de ferrugens foram encontradas parasitando plantas de interesse econômico, agronômico e florestal, utilizadas nas áreas alimentícia, frutífera, olerícola, medicinal e ornamental (tabela 3). Algumas dessas espécies foram coletadas e outras já estavam depositadas nos herbários, entre estas Puccinia xanthii Schwein. (= P. cnici-oleracei Pers. ex Desm.), ferrugem de interesse econômico para a região Amazônica, especialmente para o Estado do Pará, pois é a causadora da "ferrugem do Jambu" (Acmella oleraceae (L.) R.K. Jansen), uma planta muito consumida em pratos típicos da culinária regional (Sotão et al. 2001), e atualmente usada para aromatizar bebidas alcoólicas na região, como cachaças e licores. Acmella oleraceae também pode ser utilizada na medicina popular para tratamento de dores de garganta, sendo considerada uma planta que apresenta alto potencial para comercialização em escalas nacional e mundial (Homma et al. 2011). Puccinia xanthii parasita também, outros gêneros de plantas da família Asteraceae (Carvalho Jr. \& Sotão 2016), como Emilia e Eleutheranthera, também encontrados parasitados por esta ferrugem no presente estudo.

Aecidum alibertiae Arthur, Mycologia 14(1): 21 (1922). Tipo sobre Alibertia sp., Trinidad e Tobago: Piarco savana, ao sul de Dabadie, 21 de março, Fred J. Seaver (3286). (0/I,?/?).

Figura 3a-d

Espermogônios subepidermais, adaxiais, concêntricos, numerosos, agrupados em manchas cloróticas, pretos, associados ao écio. Écios em soros abaxiais, solitários ou agrupados, cupulados, brancos a amarelo-claros; células do perídio, $36-40 \times(17,5-) 19-25 \mu \mathrm{m}$, retangulares, romboides, com paredes interna e externa densamente verrugosa; eciósporos (19-)24-26,5 × 19-26,25 $\mu \mathrm{m}$, catenulados, globoides, subgloboides à elipsoides, pulverulentos, parede densamente verrugosa, com espessura uniforme, 1,5 $\mu \mathrm{m}$, hialina a amarela-pálida.

Material analisado: BRASIL. PArÁ: Belém, Campus da Embrapa Amazônia Oriental, sobre Alibertia edulis 


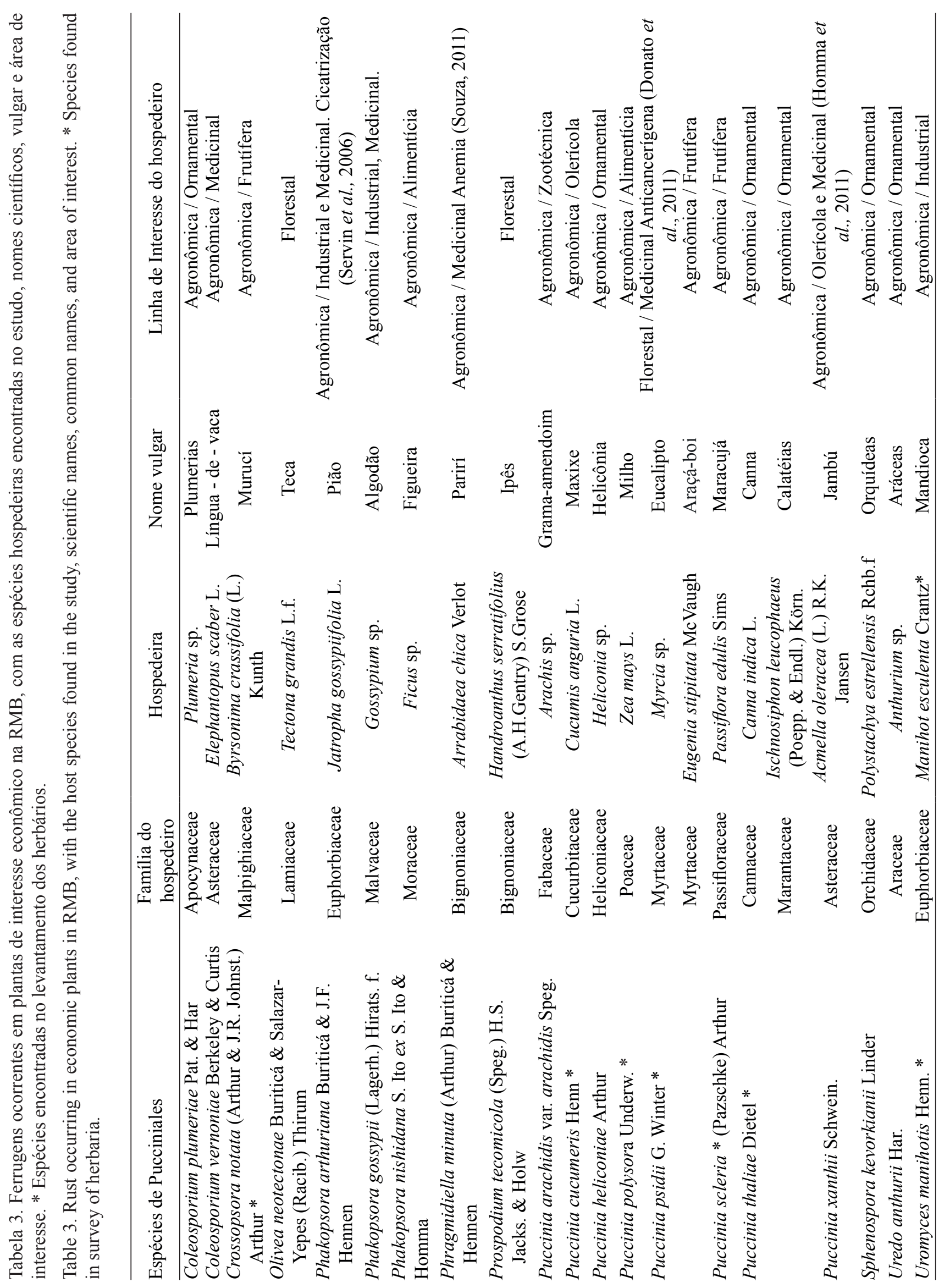


(Rich.) A.Rich. (Rubiaceae), 23-I-2013, L.T. Carmo; F.M. Brito. (MG213527, MG213531, MG213532); ibid, Alibertia sp. (Rubiaceae), L.T. Carmo; F.M. Brito (MG213538).

Esta espécie é diferenciada principalmente por apresentar esporos com ornamentação de parede

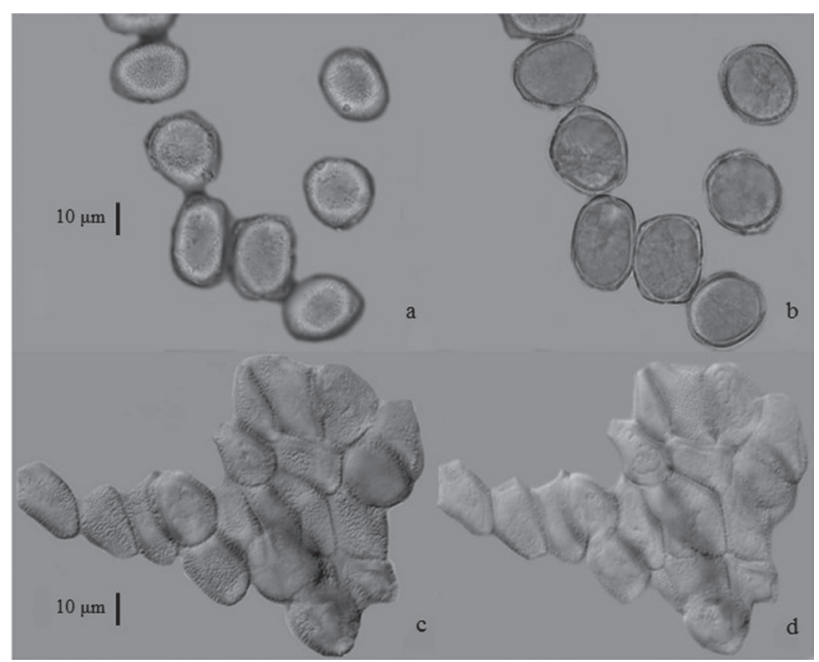

Figura 3. Novos registros de Pucciniales na Região Metropolitana de Belém, PA, Brasil. a-d. Aecidium alibertiae Arthur. a. Eciósporos, foco superficial.b.Eciósporos, foco médio. c. Células peridiais, foco superficial. d. Células peridiais, foco médio.

Figure 3. New records of Pucciniales in Belém metropolitan area, Pará State, Brazil. a-d. Aecidium alibertiae Arthur: a. Aeciospores, superficial focus. b. Aeciospores, medium focus. c. peridial cells, superficial focus. d. Peridial cells, medium focus. densamente verrugosa, com verrugas arredondadas, coloração dos esporos de hialina a amarelo claro, células peridiais fortemente unidas, densa e fortemente verrugosas, que dão a aparência aveludada, normalmente observada neste tipo de células. Segundo Arthur (1922) a espécie apresenta também espermogônios grandes, formados abaixo da epiderme, mas acima das células da camada paliçada da folha, sendo morfologicamente semelhantes aos espermogônios subcuticulares.

Não são conhecidos outros estádios do ciclo de vida, sinônimos ou ilustrações nas publicações consultadas (Arthur 1922, Sydow 1925) desta espécie de ferrugem.

A hospedeira desta ferrugem é uma planta frutífera da região amazônica, conhecida popularmente como "puruí, puruí-pequeno, apuruí e marmelada", encontrada em capoeiras de baixo porte e áreas semidescampadas (Cavalcante 2010).

Sobre Alibertia também é conhecida a espécie Puccinia farameae Kern, Ciferri \& Thurston, que apresenta somente a fase telial conhecida (Hennen et al. 2005).

Distribuição geográfica: Trinidad e Tobago (Farr \& Rossman 2016), sendo este o primeiro registro para a América do Sul, no Brasil, Estado do Pará.

Uredo philodendri Pardo-Card., Caldasia 25(2): 289 (2003). Tipo: Sobre Philodendron sp., Colombia: Antioquia: Caldas, vereda La Clara, camino al alto de San Miguel, 1.800 m, 26 mar 2000, G. Mier \& A. Franco, depositado em MMUNM, 1201. (?/?,II/?) Figura 4c

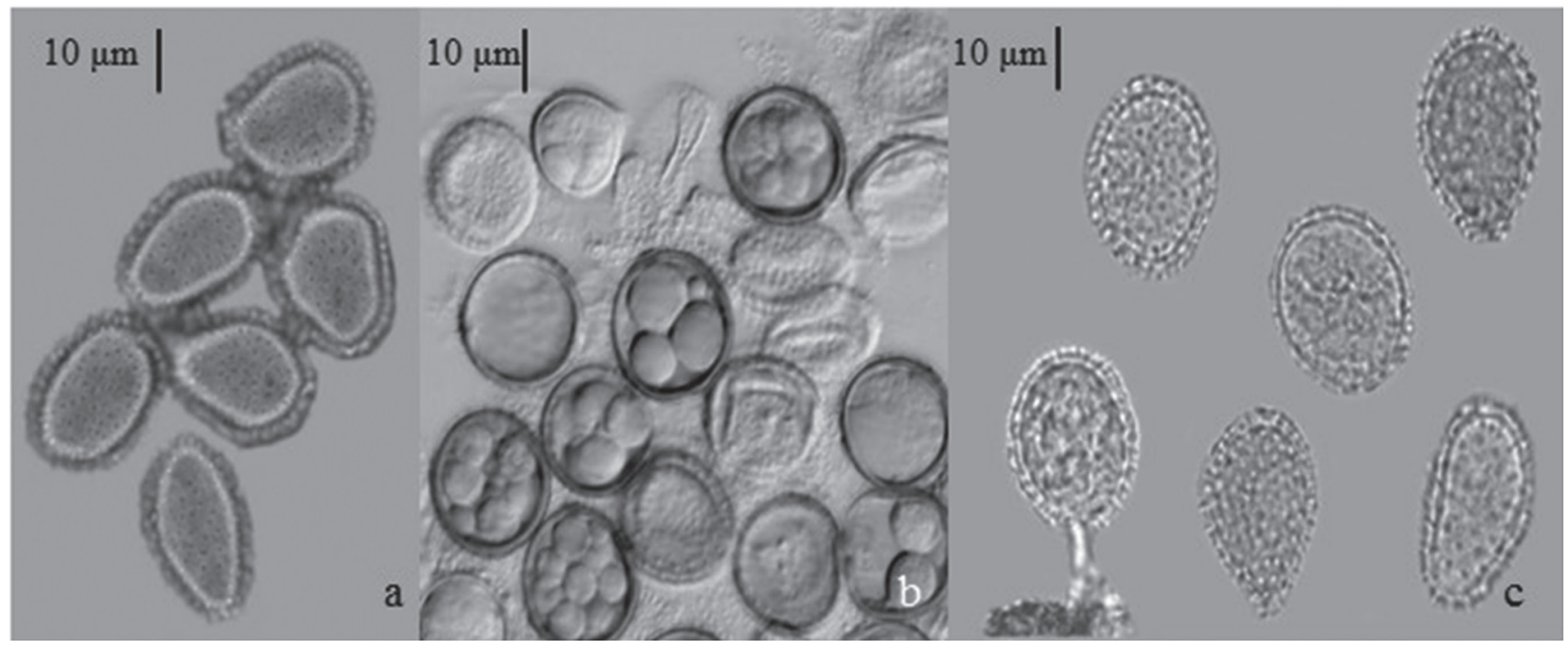

Figura 4. Novos registros de Pucciniales na Região Metropolitana de Belém, PA, Brasil. a. Puccinia commelinae Holw. b. Puccinia hyptidis-mutabilis Mayor. c. Uredo philodendri Pardo-Card, urediniósporos.

Figura 4. New records of Pucciniales in Belém metropolitan area, Pará State, Brazil. a. Puccinia commelinae Holw. b. Puccinia hyptidis-mutabilis Mayor. c. Uredo philodendri Pardo-Card, urediniospores. 
Uredínios anfígenos, predominantemente hipófilos, em manchas cloróticas, confluentes, dispersos, amarelo-claros, irrompentes, tardiamente expostos; urediniósporos, 17,5-31 × 17,5-21 $\mu \mathrm{m}$, variáveis, amplamente elipsoides, subglobosos, parede de 1,5-2,5 $\mu \mathrm{m}$, equinulada espinhosa, com equinulas de até $2,1 \mu \mathrm{m}$, mais densa e agrupadas no ápice, subhialina a amarelo-pálida, mais espessa no ápice até $3 \mu \mathrm{m}$, poros germinativos obscuros; pedicelo hialino.

Material analisado: BRASIL. PARÁ: Belém, Parque Ecológico do Município de Belém "Gunnar Vingren", sobre Philodendron (Araceae), 2-V-2013 L.T. Carmo; F.M. Brito (MG213574).

Esta espécie é caracterizada por urediniósporos de formato irregular, pela ornamentação da parede com equinulações grandes e uniformemente dispostas.

Uredo philodendri é a primeira espécie de Pucciniales registrada no Brasil sobre o gênero Philodendron Schott. No Brasil, sobre a família Araceae ocorrem as espécies Uredo anthurii Har., sobre o gênero Anthurium; e Uredo monsterae Syd. sobre Monstera, ambas registradas na Amazônia (Hennen et al. 2005, Sotão et al. 2009). Uredo philodendri pode ser diferenciada de $U$. anthurii pelos esporos que apresentam morfologia variável, com ornamentação espinhosa mais densa e agrupada no ápice e pigmentação amarelada, enquanto que $U$. anthurii apresenta morfologia mais regular, obovoide a amplamente elipsoides, parede amarelopálida a marrom-canela, ornamentação forte e uniformemente equinulada (Salazar-Yepes \& Carvalho Jr. 2010), e poros germinativos obscuros ou 4, mais ou menos equatoriais (Hennen et al. 2005).

Distribuição geográfica: Esta espécie era somente reportada para a Colômbia (Pardo-Cardona 2003, Pardo-Cardona 2006), sendo este o primeiro registro para o Brasil, no Estado do Pará.

\section{Conclusão}

Os novos registros de espécies de ferrugens e de plantas hospedeiras representam um incremento na riqueza de espécies de fungos Pucciniales do Brasil, da Amazônia e para a Região Metropolitana de Belém. A RMB apresenta a maior riqueza de espécies de fungos Pucciniales conhecida na Amazônia.

\section{Agradecimentos}

Aos Laboratórios de Micologia do MPEG, da Universidade Federal do Pará (UFPA) e da
Universidade Estadual de Feira de Santana (UEFS) e pela infraestrutura cedida na realização deste trabalho; aos Técnicos Luis Carlos Lobato, Elielson Rocha e Mário Rosa do MPEG, pelas identificações botânicas e apoio nas coletas; à CAPES/PNADB e $\mathrm{CNPq} /$ Protax (processo $\mathrm{n}^{\circ}$ 922-2010) pelo apoio financeiro recebido. A Priscila Medeiros pelas análises estatísticas. À Secretaria de Estado de Meio Ambiente do Pará, Secretaria Municipal de Meio Ambiente de Belém, Embrapa Amazônia Oriental e ao Sr. Hirakata Ko gerente do Parque Ecológico de GUNMA, pela concessão das licenças de coleta e apoio durante a etapa de campo; ao Programa de Pós-graduação em Ciências Biológicas, área de concentração Botânica Tropical (Universidade Federal Rural da Amazônia - UFRA/ MPEG), pelo apoio oferecido e a primeira autora agradece ao Conselho Nacional de Desenvolvimento Científico e Tecnológico (CNPq), pela bolsa concedida.

\section{Literatura citada}

Aime, M.C., Matheny, P.B., Henk, D.A., Frieders, E.M., Nilsson, R.H., Piepenbring, M., Mclaughlin, D.J., Szabo, I.J., Begerow, D., Sampaio, J.P., Bauer, R., Weiß, M., Oberwinkler, F. \& Hibbett, D. 2006. An overview of the higher level classification of Pucciniomycotina based on combined analyses of nuclear large and small subunit rDNA sequences. Mycologia. 98: 896-905.

Albuquerque, F.C. 1971 a. Relação das espécies de Uredinales coletadas na Amazônia. Pesquisa Agropecuária Brasileira, Série Agronomia. v. 6, pp. 147-150.

Albuquerque, F.C. 1971b. Descrição de cinco novas espécies de Uredinales da Amazônia. Pesquisa Agropecuária Brasileira, Série Agronomia. v. 6, pp. 139-143.

Albuquerque, F.C. \& Figueiredo, M.M. 1971. Descrição de uma nova espécie de Uredinales da Amazônia Uromyces belemensis. Pesquisa Agropecuária Brasileira, Série Agronomia 6, pp. 145-146.

Almeida, A.S., Vieira, I.C.G. 2010. Centro de Endemismo Belém: Status da vegetação remanescente e desafios para a conservação da biodiversidade e restauração ecológica. Revista de Estudos Universitários. v. 36, n. 3, pp. 95-111.

Amaral, D.D., Vieira, I.C.G., Almeida, S.S., Salomão, S.P., Silva, A.S.L. \& Jardim, M.A.G. 2009. Checklist da flora arbórea de remanescentes florestais da região metropolitana de Belém e valor histórico dos fragmentos, Pará, Brasil. Boletim do Museu Paraense Emílio Goeldi. Ciências Naturais. 4: 231-289. 
Ananindeua. 2011. Lei no . 2.472, de 5-I-2011. Disponível em http://www.ananindeua.pa.gov.br/public/arquivos/ legislacao/LEI_No._2.472.pdf(acesso em 17-I- 2014).

Arthur, J.C. 1922. Uredinales collected by R. Thaxter and J.B. Rorer in Trinidad. Botanical Gazette Crawfordsville. 73: 58-69.

Arthur, J.C. 1925. Uredinales. Additions and corrections. North American Flora 7: 669-732.

Batista, A.C., Falcão, R.G.S., Peres, G.P.E. \& Moura, N.R. 1966. Fungi Paraenses. Instituto de Micologia da Universidade Federal de Pernambuco. v. 506, pp. 1-290.

Berndt, R. 2007. A global survey of Puccinia-rust on Cucurbitaceae. Mycol Progress (2007) 6:151-178.

Berndt, R. 2012. Species richness, taxonomy and peculiarities of the neotropical rust fungi: are they more diverse in the Neotropics? Biodiversity and Conservation. v. 21, pp. 2299-2322.

Berndt, R. 2013. First catalogue of the rust fungi of French Guiana, northern South America. Mycol Progress 12: 193-211.

Buriticá, P. 2003. Centros naturales de diversificación en el orden Uredinales (Fungi, royas). Revista Facultad Nacional de Agronomía Medellín. 56: 1999-2019.

Carvalho Jr., A.A. \& Sotão, H.M.P. 2010. Pucciniales. In: R.C. Forzza, J.F.A. Baumgratz, C.E.M. Bicudo, A.A. Carvalho Jr., A. Costa, D.P. Costa, M. Hopkins, P.M. Leitman, L.G., Lohmann, L.C. Maia, G. Martinelli, M. Menezes, M.P. Morim, M.A.N. Coelho, A.L. Peixoto, J.R. Pirani, J. Prado, L.P. Queiroz, V.C. Souza, J.R, Stehmann, L.S. Sylvestre, B.M.T. Walter \& D. Zappi (eds.). Catálogo de Plantas e Fungos do Brasil, v. 1. Andrea Jakobsson Estúdio/Instituto de Pesquisa do Jardim Botânico do Rio de Janeiro, Rio de Janeiro. pp. 210-242.

Carvalho Jr., A. A. \& Sotão, H.M.P. 2016. Pucciniales in Lista de Espécies da Flora do Brasil. Jardim Botânico do Rio de Janeiro. Disponível em http://floradobrasil.jbrj. gov.br/jabot/floradobrasil/FB25 (acesso em VI-2016).

Carvalho Jr., A.A., Figueiredo, M.B., Furtado, L.L., Hennen, J.F. 2002. Micota uredinóloga da reserva florestal "Armando de Salles Oliveira", São Paulo, Brasil: sobre Amaranthaceae, Asclepiadaceae, Bignoniaceae e Boraginaceae. Hoehnea 29: 19-30.

Carvalho Jr., A.A., Hennen, J.F. \& Figueiredo, M. B. 2001. Primeira constatação do teleomorfo da ferrugem (Kweillingia divina) do Bambu (Bambusa vulgaris) nas Américas. Summa Phytopathologica. v. 27, n. 2.

Cavalcante, P.B. 2010. Frutas comestíveis na Amazônia. 7 ed. revisada e atualizada. Museu Paraense Emílio Goeldi, Belém.

Colwell, R.K. 2006. EstimateS: statistical estimation of species richness and shared species from samples. Disponível em http://purl.oclc.org/estimates. (acesso em V-2015).
Cummins, G. B. 1940. Descriptions of tropical rusts - II. Bull. Torrey Bot. Club 67: 67-75.

Cummins, G.B. 1971. The rust fungi of cereals, Grasses and Bamboos. Editora Spinger-Verlag, New York.

Cummins, G. B. \&Hiratsuka, Y. 2003. Illustrated Genera of Rust Fungi. 3 ed. The American Phytopathological Society, St. Paul, Minnesota, pp. 1-225.

Dietel, P. 1909. Uredinaceae paraenses. Boletim do Museu Paraense Emílio Goeldi. n. 5, pp. 262-267.

Donato, A.M. \& Morretes, B.L. 2011. Morfo-anatomia foliar de Myrcia multiflora (Lam.) DC. - Myrtaceae. Revista Brasileira de Plantas Medicinais, v. 13, n. 1.

Farr, D.F. \&Rossman, A.Y. 2016. Fungal Databases, Systematic Mycology and Microbiology Laboratory, ARS, USDA. Disponível em http://nt.ars-grin.gov/ fungaldatabases/ (acesso em 20-V-2016).

Ferreira, L.V., Parolin, P., Muñoz, S.H. \& Chaves, P.P. 2012. O efeito da fragmentação e isolamento florestal das áreas verdes da Região Metropolitana de Belém. Instituto Anchietano de Pesquisas, n. 63, pp. 357-367.

Fidalgo, O. \& Bononi, V.L.R. 1989. Técnicas de coleta, preservação e herborização de material botânico. São Paulo: Instituto de Botânica.

França, I.F. \& Sotão, H.M.P. 2009. Novos registros de Ferrugens (Uredinales) sobre Fabaceae para o Brasil. Acta Botânica Brasilica, v. 23, n. 3, pp. 860-863.

França, I.F., Sotão, H.M.P. \& Costa-Neto, S.V. 2010. Fungos causadores de ferrugens da Reserva Biológica do Lago do Piratuba, Amapá, Brasil. Rodriguesia 61: 211-221.

Hennen, J.F. \& Freire, F.O. 1979. Apra a new genus of Uredinales on Mimosa from Brazil. Mycologia.71: 1053-1057.

Hennen, J. F. \& Lopéz, A.R. 1995. Aecidium byrsonimatis (Uredinales) on Byrsonima (Malpighiaceae). Centro de Genética Forestal. Universidad Veracruzana. Notas Técnicas 27:1-8.

Hennen, J.F. \& Sotão, H.M.P. 1996. New species of Uredinales on Bignoniaceae from Brazil. Sida. v. 17, n. 1, pp. 173-184.

Hennen, J.F., Figueiredo, M.B., Carvalho Jr., A.A. \& Hennen, P.G. Catalogue of plant rust fungi (Uredinales) of Brazil. 2005. Disponível em http://www.jbrj.gov.br (acesso em 20-VI-2016).

Hennen, J.F., Subrahmanyam, P. \& Figueiredo, M.B. 1987. Groundnut Rust Disease. The taxonomy, life history, and evolution of Puccinia arachidis Speg. Patancheru. ICRISAT, pp. 145-155.

Hennings, P. 1900. Fungi Paraenses I. Hedwigia Beihefte. v. 39, n.3, pp.76-80.

Hennings, P. 1902. Fungi Paraenses II. cl. Dr. J. Huber collecti. Hedwigia Beihefte. v. 4., pp.15-18.

Hennings, P. 1908. Fungi Paraenses-III. Hedwigia. v. 48, pp.101-117. 
Hibbett, D.S., Binder, M., Bischoff, J.F., Blackwell, M.R., Cannon, P.L.F., Ove E., Eriksson, Huhndorf, S., James, T., Kirk, P.M., Lücking, R., Lumbsch, H.T., Lutzoni, F., Matheny, P. B., Mclaughlin, D.J., Powell, M.J., Redhead, S., Schoch, C.L., Spatafora, J.W., Stalpers, J.A., Vilgalys, R.S., Aime, M. C., Aptroot, A., Bauer, R., Begerow, D., Benny, G.L., Castlebury, L.A., Crous, P.W., Dai, Y., Gams, W., Geiser, D.M., Griffith,G.W., Gueidan, C., Hawksworth, D.L., Hestmark, G., Hosaka, K., Humber, R.A., Hyde, K.D., Ironside, J.E., Kõljalg, U., Kurtzman, C.P., Larsson, K.H., Lichtwardt, R., Longcore, J., Miądlikowska, J., Miller, A., Moncalvo, J.M., Mozley-Standridge, S., Oberwinkler, F., Parmasto, E., Reeb, V., Rogers, J.D., Roux, C., Ryvarden, L., Sampaio, J.P., Schüßler, A., Sugiyama, J., Thorn, G., Tibell, L., Untereiner, W.A., Walker, C., Wang, Z., Weir, A., Weiss, M., White, M.M., Winka, K., Yao, Y. \& Zhang, N. 2007. A higher-level phylogenetic classification of theFungi. Mycological Research, v. 111, n. 5, pp. 509-547.

Homma, A.K.O., Sanches, R.S., Menezes, A.J.E.A. \& Gusmão, S.A.L. 2011. Etnocultivo do jambu para abastecimento da cidade de Belém, Estado do Pará. Amazônia: Ciência \& Desenvolvimento, v. 6, n. 12, pp. 125-141.

Holway, E.W.D. 1904. Mexican Uredineae. Annales Mycologici. 2:391-394.

Jackson, H.S.1926. The rusts of South America based on the Holway Collections - I.Mycologia 18: 139-162.

Kirk, P.M., Cannon, P.F., David, J.C. \& Stalpers, J. 2008. Ainsworth \& Bisby's dictionary of Fungi. 10th. Editora Surrey: CABI Publishing.

Kress, W.J. \& Specht, C.D. 2005. Between Cancer and Capricorn:phylogeny, evolution and ecology of the primarily tropical Zingiberales. Biol. Skr. 55: 459-478.

Laundon, G.F. 1963. Rust fungi 1: On Acanthaceae. Mycological Papers 89: 1-89.

López, A. \& Hennen, J. 1995. Aecidium vinnulum (Uredinales) on Byrsonima (Malpighiaceae). Notas Técnicas del Centro de Genética Forestal, Universidad Veracruzana 27:1-2.

Maia, L.C. Maia, L.C., Carvalho-Júnior, A.A., Cavalcanti, L.H., Gugliotta, A.M., Drechsler-Santos, E.R., Santiago, A.L.M.A, Cáceres, M.E.S., Gibertoni, Aptroot, A., Giachini, A.J., Soares, A.M.S., Silva, A.C.G., Magnago, A.C., Goto, B.T., Lira, C.R.S., Montoya, C.A.S., Pires-Zottarelli, C.L.A., Silva, D.K.A., Soares, D.J., Rezende, D.H.C., Luz, E.D.M.N., Gumboski, E.L., Wartchow, F., Karstedt, F., Freire, F.M., Coutinho, F.P., Melo, G.S.N., Sotão, H.M.P., Baseia, I.G., Pereira, J., Oliveira, J.J.S., Souza, J.F., Bezerra, J.L., Araujo Neta, L.S., Pfenning, L.H., Gusmão, L.F.P., Neves, M.A., Capelari, M., Jaeger, M.C.W., Pulgarín, M.P., Menolli Junior, N., Medeiros, P.S., Friedrich, R.C.S., Chikowski, R.S., Pires, R.M., Melo, R.F., Silveira, R.M.B., Urrea-Valencia, S., Cortez, V.G. \& Silva, V.F. 2015. Diversity of Brazilian Fungi.Rodriguésia 66: 1033-1045.
Mains, E.B. 1935. Rust and Smuts from the Yucatan Peninsula. Carnegie Institution of Washington Publication 461: 93-106.

Mayor, E. 1913. Contribution a l'étude des Uredinées de Colombie. Mémoires de la Société des Sciences Naturelles de Neuchâtel 5: 442-599.

MMA - Ministério do Meio Ambiente. 2007. Ministério do Meio Ambiente. Áreas Prioritárias para Conservação, Uso Sustentável e Repartição de Benefícios da Biodiversidade Brasileira: Atualização - Portaria MMA $\mathrm{n}^{\circ}$ 9, de 23 de janeiro de 2007.

Mori, S.A., Smith, N.P., Cornejo, X. \& Prance. G.T. Lecythidaceae Pages. Disponível em http://sweetgum. nybg.org/lp/index.php (acesso em 04-II-2014).

Pardo-Cardona, V.M. 2003. Nuevas especies y registros de Uredinales para Colombia y Sudamérica. Caldasia 25: 283-296.

Pardo-Cardona, V.M. 2006. Uredinales de plantas cultivadas de interés floral en Colombia. Revista de la Facultad Nacional Agronomía de Medellín 59: 3335-3353.

Pieri, C., Passador, M.M., Furtado, E.L.\& Carvalho Jr, A.A. 2011. Ferrugem da teca (Olivea neotectonae): novas ocorrências no Brasil e revisão do nome específico. Summa Phytopathol., Botucatu, v. 37, n. 4, pp. 199-201.

Poltronieri, L.S., Verzignassi, J.R., \& Benchimol, R.L. 2013. Puccinia heliconiae: agente causal da ferrugem em Heliconia cv. Golden Torch no Pará. Summa Phytopathol., Botucatu, v. 39, n. 3, pp. 213.

Rodríguez, M.A.D., Oliveira, A.M.G., Diniz, M.S. \& Alves, A.A.C. 2008. Ferrugem da Mandioca. Embrapa Mandioca e Fruticultura Tropical, Comunicado técnico 37. Disponível em http://ainfo.cnptia.embrapa.br/digital/ bitstream/CNPMF-2009-09/25300/1/mandioca_37.pdf (acesso em VI-2016).

Salazar-Yepes, M. \& Carvalho Jr., A.A. 2010. Ferrugens: diversidade de Uredinales do Parque Nacional do Itatiaia, Brasil. Rio de Janeiro: Technical Books.

Salazar-Yepes, M. \& Carvalho Jr., A.A. 2013. Uredinales (rust fungi) biota of the Parque Nacional do Itatiaia, Brazil: an analysis of composition, species diversity and altitudinal distribution. Caldasia 35: 165-176.

Servin, S.C.N., Torres, O.J.M., Matias, J.E.F., Agulham, M.A., Carvalho, F.A., Lemos, R., Soares, E.W.S., Soltoski, P.R. \& Freitas, A.C.T. 2006. Ação do extrato de Jatropha gossypiifolia L. (pião roxo) na cicatrização de anastomose colônica: Estudo experimental em ratos. Acta Cirúrgica Brasileira, v. 21, suplemento 3, pp. 89-96.

Silva, J.M.C. 2011. Belém. In: R. Valente, J.M.C. Silva, F.C. Straube, \& J.L.X. Nascimento (orgs.). Conservação de aves migratórias neárticas no Brasil. Conservação Internacional, Belém, pp. 82-87. 
Sotão, H.M.P., Hennen, J.F. \& Cavalcante, M.A. 2001. Uredinales do Estado do Amapá: o gênero Puccinia. Boletim do Museu Paraense Emílio Goeldi, Série Botânica, v. 17, n. 1, pp. 107-159.

Sotão, H.M.P., França, I.F. \& Hennen, J.F. 2006. Fungos das famílias Phakopsoraceae e Uropyxidaceae (Uredinales) da Floresta Nacional de Caxiuanã, Pará, Brasil. Hoehnea 33: 407-417.

Sotão, H.M.P., Hennen, J.F., França, I., Freires, E., Moura, M.F., Martins, Jr.A., Medeiros, P.S. \& Silva, M.F.F. 2009. Ferrugens (Uredinales - Basidiomycota) da Flona de Caxiuanã. In: P.L.B. Lisboa (orgs.).Caxiuanã: desafios para a conservação de uma floresta nacional na Amazônia. Museu Paraense Emílio Goeldi, Belém, pp. 371-381.

Sotão, H.M.P., Hennen, J. F., Freire, E., Mendonça, F., Brito, F., França, I. \& Castro, C. 2013. Novos Registros de fungos (Pucciniales) para a Floresta Nacional de Caxiuanã, Amazônia e Brasil. In: P.L.B. Lisboa(orgs.). Caxiuanã. Paraíso ainda preservado. Museu Paraense Emílio Goeldi, Belém, pp. 367-374.
Souza, A.J.A. 2011. Uso de plantas medicinais no município de Benevides/Pará: elaboração do memento fitoterápico e construção da política municipal de plantas medicinais e fitoterápicos. Dissertação de Mestrado, Universidade Federal do Pará, Pará.

Suassuna, N.D. \& Araújo, A.E. 2003. Ferrugem "Tropical" do Algodoeiro. Embrapa Algodão. Documentos, n. 114.

Sydow, H. 1925. Rusts of British Guiana and Trinidad. Mycologia 17: 255-262.

Sydow, H. \& Sydow, P. 1916. Fungi Amazonia C.L. E. Ule lecti. Annales Mycologici, v. 34, pp. 69-97.

To-Anun, C., Visarathanonth, N., Engkhaninun, J., \& Kakishima, M. 2004. First Report of Plumeria Rust, Caused by Coleosporium plumeriae, in Thailand. The Natural History Journal of Chulalongkorn University 4: 41-46.

Viégas, A.P. 1945. Alguns fungos do Brasil IV - Uredinales. Bragantia, v. 5, n. 1.

Viégas, A.P. 1960. Uma ferrugem do Saguaragi. Bragantia 19: 101-102.

Vázquez-Marrufo, G., Vázquez-Garcidueñas, M. S. \& Mukhtar, I. 2014. Uromyces euphorbiae on Euphorbia hirta. From Guerreroand Michoacan (Mexico): First report. Bangladesh. Journal of Botany 43: 375-376. 